\title{
Marcas do inconsciente: grafite, psicanálise e possíveis interlocuções
}

\section{RICHARD PERASSI LUIZ DE SOUSA \\ TAÍS AZAMBUJA ALVES DE LIMA}

\section{Resumo}

O conceito de cidade inteligente aborda questões socioambientais, culturais, econômicas, artísticas, tecnológicas, entre outras. A saber, a estratégia para o trabalho inovador que investe no capital intelectual é articulada aos processos criativos em geral e aos artísticos em particular, sendo isso fundamental na dinâmica da atualidade. Este ensaio busca elucidação do conhecimento, por meio de identificação e interpretação, dos elementos característicos de expressão local da arte grafite. Para tanto, será utilizada a teoria psicanalítica como fundamento

Palavras-chave: Cidade inteligente, grafite, psicanálise epistêmico aplicável à produção do conhecimento em geral. Propõe-se a articulação entre o grafite e a psicanálise em extensão, ou seja, no mundo, na cultura. 


\section{Unconscious marks: graffiti, psychoanalysis and possible dialogue}

Abstract

The smart city concept addresses socio-environmental, cultural, economic, artistic, technological issues, among others. Namely, the strategy for the innovative work that invests in intellectual capital is articulated to the creative processes in general and art in particular, and this is fundamentalin nowadays' today's dynamic. This assay seeks elucidation of knowledge through the identification and interpretation of the characteristic local expression of graffiti art. For this purpose, it will be used psychoanalytic theory as epistemic foundation applied to the production of knowledge in general. It is proposed the joint between the graffiti and psychoanalysis in extension, that is to say, in the world, in the culture.

Keywords:

Smart city, graffiti, psychoanalysis 


\section{Marcas del inconsciente: grafiti, psicoanálisis y posibles interlocuciones}

\section{RICHARD PERASSI LUIZ DE SOUSA \\ TAÍS AZAMBUJA ALVES DE LIMA}

\section{Resumen}

El concepto de ciudad inteligente envuelve temas socioambientales, culturales, económicos, artísticos, tecnológicos, entre otros. Como bien sabemos, la estrategia para el trabajo innovador que invierte en el capital intelectual se articula a los procesos creativos en general y a los artísticos en particular, ya que eso, es fundamental en la actual dinámica. Este ensayo tiene el objetivo de elucidar el conocimiento, por medio de la identificación e interpretación de los elementos característicos de la expresión local del arte grafiti. Para ese propósito, se usará la teoría psicoanalítica como fundamento epistemológico

Palabras-clave: Ciudad inteligente, grafiti, psicoanálisis aplicable a la producción de conocimiento en general. Se propone la articulación entre el grafiti y el psicoanálisis en extensión, o sea, en el mundo, en la cultura. 


\section{Introdução}

"Onde os grafites gritam

Não dá pra descrever".

(Criolo)

Há estudos sendo desenvolvidos na região Lagoa da Conceição, na Ilha de Santa Catarina, da cidade Florianópolis, considerando o tema "cidades inteligentes", sobre mobilidade urbana, acesso a serviços, qualidade de vida, integração cultural e social. Portanto, trata-se de apresentar aqui um recorte específico, mas que também propõe argumentos e embasamentos teóricos que sustentaram outros artigos já publicados (LIMA; SCHMIEGELOW; PERASSI, 2016a, 2016b).

O projeto de estruturação do ambiente urbano, como cidade inteligente, requer o levantamento de informações diversas sobre aspectos subjetivos e objetivos da cultura local. Está em questão a relação eficiente entre a cidade "desejada" e a cidade "possível".

Sobre o "possível", deve-se considerar os estudos de gestão pública em seus diversos aspectos: políticos, sociais, econômicos, tendo em vista as relações conceituais, ideológicas, estruturais e econômico-financeiras. Porém, o conhecimento sobre a cidade "desejada" requer processos de interpretação da intersubjetividade urbana, a partir da expressão de agentes representativos do senso comunitário.

Retoma-se aqui, mais uma vez, as ideias de Ezra Pound (1885-1972), poeta, músico e crítico literário estadunidense, o qual enunciou "os artistas são as antenas da raça", reafirmando a crença generalizada de que a sensibilidade e a intuição do artista são premonitórias, com relação ao espírito do tempo vivido (zeitgeist). Também, recupera-se a evocação hegeliana do 
espírito ou do sentido de uma época, como é filosoficamente reconhecido também por Friedrich Nietzsche (1844-1900).

No livro "Guerra e Paz", Leon Tolstoi (1828-1910) declara: "se queres ser universal começa por pintar a tua aldeia". A afirmação não se baseia em comprovações científicas, mas seu valor filosófico universal é evidenciado por percepções e estudos descritivos do fenômeno artístico que foram produzidos em diferentes localidades ao longo do percurso histórico.

Atualmente, a frase "pintar a tua aldeia" tem sido considerada literalmente, porque não representa apenas a metáfora que sugere a aldeia como motivação primeira da arte. Pois, a prática da arte de rua, geralmente denominada de "Graffiti", recobre com pinturas os muros e as paredes externas das áreas urbanas. Assim, faz décadas que Grafite é considerado um tipo de arte urbana tipicamente popular e contemporânea.

A arte grafite possui uma história subversiva, marginal e excêntrica. O autor Celso Gitahy (2012) defende que a primeira manifestação desta arte é reconhecidamente a arte rupestre, a arte das paredes das cavernas são os primeiros registros de grafite na história da arte.

A palavra "grafite", oriunda da terminologia italiana graffto, cujo plural é graffiti, designa diversos tipos de manifestação urbana, como escrituras, desenhos e pinturas murais. Desde o império romano até o final do século XX, manifestações em graffito ou grafite, via de regra, foram percebidas e tratadas como contravenção à ordem pública, por serem resultantes de manifestações clandestinas realizadas sem prévia autorização do lado externo de paredes e muros do ambiente urbano.

O Grafite já foi disseminado na quase totalidade das cidades do planeta Terra. Todavia, assim como na arte em geral, também, as inscrições e as pinturas grafitadas expressam características típicas, distinguindo as obras realizadas por diferentes artistas, de acordo com os valores individuais e locais.

As superfícies externas da arquitetura que compõe a região urbana em torno da Lagoa da Conceição em Florianópolis são especialmente decoradas com escrituras e pinturas grafitadas. Há na região, um grupo de artistas de rua que são parcialmente responsáveis pela ocupação das paredes e dos muros em diversas localidades da cidade. Contudo, considera-se que, de algum modo, as manifestações desses artistas são distintas ou peculiares devido à sua marca regional de origem. A saber, a particularidade, singular em cada um dos artistas, marca os muros e paredes da Lagoa da Conceição. 
Uma marca é um sinal, porque sua propriedade básica é ter expressividade, sendo percebida pelos sentidos humanos: visão, audição, olfato, tato e paladar (PERASSI, 2005). Quando o sinal é interpretado, sendo associado a outras coisas e representando-as, o mesmo passa a ser percebido e lido como um signo. Pois um signo é o sinal cuja expressão representa outra coisa diferente de si mesmo. Representa algo para alguém.

\section{Grafite e psicanálise, interlocuções}

Há algumas décadas, os muros e paredes de cidades, em diferentes localidades do planeta, estão cobertos de palavras, grafismos e pinturas que, geralmente, são realizados por jovens. Há uma parte da população que os percebe como "pichadores". Mas, também, há grafiteiros que são reconhecidos como artistas, por uma parcela das pessoas que aprenderam distinguir e apreciar o que há de mais qualificado nessas manifestações.

Atualmente, há artistas mundialmente reconhecidos por seus trabalhos de rua, os quais são oficialmente convidados para produzir ou expor grafites em locais públicos ou em ambientes institucionais especializados, como museus e galerias de arte.

Por exemplo, na primeira semana do mês de março do ano 2014, na galeria Luciano Martins, localizada na Lagoa da Conceição em Florianópolis, aconteceu a exposição "Graffiti em Recorte". A mostra reuniu dez grafiteiros, sendo alguns atuantes em Florianópolis e outros em São Paulo. A organização foi do Instituto Lagoa Social e a curadora responsável foi Myrine Vlavianos.

Mais recentemente, sucedeu na região da Lagoa da Conceição, a "Primeira Feira de Arte Urbana e Ideias", nas datas 15 e 16 de novembro de 2014. Promovida por artistas locais, como também pela iniciativa de algumas pessoas interessadas em encontros de arte, a feira aconteceu em um lugar propício ao aconchego dos participantes e expectadores, mesclado à exposição artística e bom som.

O local que sediou a feira tem o nome Tienda de Ideias. Localiza-se em uma esquina colorida da Lagoa da Conceição, um espaço social e geográfico privilegiado pela beleza, tanto da natureza quanto do convívio cultural, bem como da arte urbana que marca este lugar.

Entre os artistas grafiteiros radicados no contexto cultural da localidade Lagoa da Conceição em Florianópolis, destacam-se: Pedro Driin que está no local há 15 anos e Paulo Govea 
que, há mais de uma década, mora no entorno e frequenta a localidade. Há artistas naturais da Lagoa, os quais são Daniel Barcellos, Danka Umbert e Douglas Augusto, dentre outros, que colorem e expressam sua arte no lugar em que nasceram.

Anteriormente, todo tipo de grafite era considerado crime. Mas, mesmo na marginalidade, os grafiteiros resistiram e, aos poucos, subverteram a visualidade e a realidade da cidade. Há diferentes motivações e decorrências relacionadas com as expressões grafitadas, às vezes, evidenciando a revolta e o protesto ou enfatizando o caráter lúdico ou estético-subjetivo que são comuns às manifestações artísticas.

Como os sonhos, inscrições, desenhos e pinturas expressam situações da realidade na linguagem típica do inconsciente. Além das denotações aparentes, das sensações e das impressões estéticas, metaforicamente, também há mensagens "criptografadas" sobre o que habita o inconsciente.

De acordo com Orlandi (2004), o grafite é uma manifestação urbana que, através de formas e cores, expressa contradições entrelaçadas na teia de relações urbanas. Assim, as obras de grafite podem revelar distintos significados, atrelados à convivência entre os seres humanos nas cidades.

O próprio Sigmund Freud (1856-1939) assinalou que o ser humano é criativo e também interacional, caracterizando-se como ser social. Portanto, a vida mental do indivíduo, que permite a constituição da psicologia individual, ao mesmo tempo, permite também a psicologia social (FREUD, 2006).

O inconsciente inaugura um lugar, em Freud, é um lugar obscuro, desconhecido, permeado de simbolismo e representação. $\mathrm{O}$ inconsciente é um enigma a ser desvendado, desvelado, descoberto, conhecido cotidianamente, através de suas formações de compromisso ${ }^{1}$, bem como de suas produções manifestas. Mas, a gênese do inconsciente articula-se com a história (contexto) de cada sujeito. Em cada ser humano há representações inscritas no inconsciente que comumente não são conhecidas e permanecem na obscuridade. "Certamente, só o conhecemos como algo consciente, depois que ele sofreu transformação ou tradução para algo consciente." (FREUD, 2006, p.171). Assim, o inconsciente profere suas próprias marcas, as quais devem ser interpretadas.

De acordo com Freud, há interesse da psicanálise pela estética. Na expressão da arte, para este autor, está vinculada a atividade de abrandar desejos insatisfeitos, deste modo, a produção artística promove a libertação de desejos inconcebíveis, impensados, emersos em significados inconscientes. Como campo de conhecimento fundado por Freud, Psicanálise se re- 
laciona com Estética, que é um enfoque interessante para psicologia social e também para a psicologia individual.

Neste artigo, os nomes das figuras, as escrituras representadas nas obras de grafite e partes da fala dos grafiteiros são identificadas como marcas do inconsciente. Metaforicamente, as marcas do inconsciente são como as pegadas na areia, devido ao percurso dos que caminham. São expressas nos atos e efeitos da linguagem. Isso requer procedimentos para identificar, observar, registrar e simbolizar essas marcas, conhecendo os significados dessas expressões.

A região da Lagoa é convencionada como um lugar alternativo, pois comporta restaurantes, bares, hostel's, hotéis, galerias de arte e comércios em geral, reúne pessoas de diversos lugares do mundo. E simultaneamente ateia a original cultura local, como a prática de pesca da Costa da Lagoa, e as famosas mulheres rendeiras, produtoras de artesanato, produtoras de significados. A capoeira também compõe este universo repleto de imagem da diversidade que é a Lagoa.

A imagem é formadora da função eu, em psicanálise, representa uma identificação imaginária, como uma unidade, como algo total. Em psicanálise não existe a totalidade, a completude de um eu, sempre estamos sujeitos à imagem especular. Aqui se pode pensar em sintoma, ou seja, em cristalização de conflitos entre o que pode ser visto e dito, imageticamente, e o que não pode ser dito. A imagem, comumente, transporta uma repressão.

Tania Rivera (2013, p.65), psicanalista e atuante crítica das artes, defende que "a imagem pode ser um pictograma, uma escrita visual, dissemina-se em múltiplas referências". Uma imagem informa algo que se pode dizer e algo que se deve calar. A imagem sempre é distorcida pela repressão, é um dito não dito.

Imagem e letra são entrelaçadas na arte urbana, também denominada grafite, e como aponta Lacan (1964), os processos pelos quais as imagens são formadas representam figuras de linguagem, a metáfora e a metonímia. As imagens, diz o dito popular, valem mais do que mil palavras, e elas de fato anunciam, entretanto, o que as imagens compõem muitas vezes as palavras não conseguem dizer. As imagens são simbólicas.

O contexto urbano da Lagoa da Conceição simboliza um lugar diferenciado, os transeuntes que se movimentam neste contexto percebem como a região é colorida e escrita pela arte grafite. O que este grafite específico da Lagoa deseja expressar? Esta é a questão que se almeja discutir neste artigo.

Em relação ao grafite da Lagoa, os artistas (os quais a autora contatou por meio de aproximação e contatos em entrevistas) 


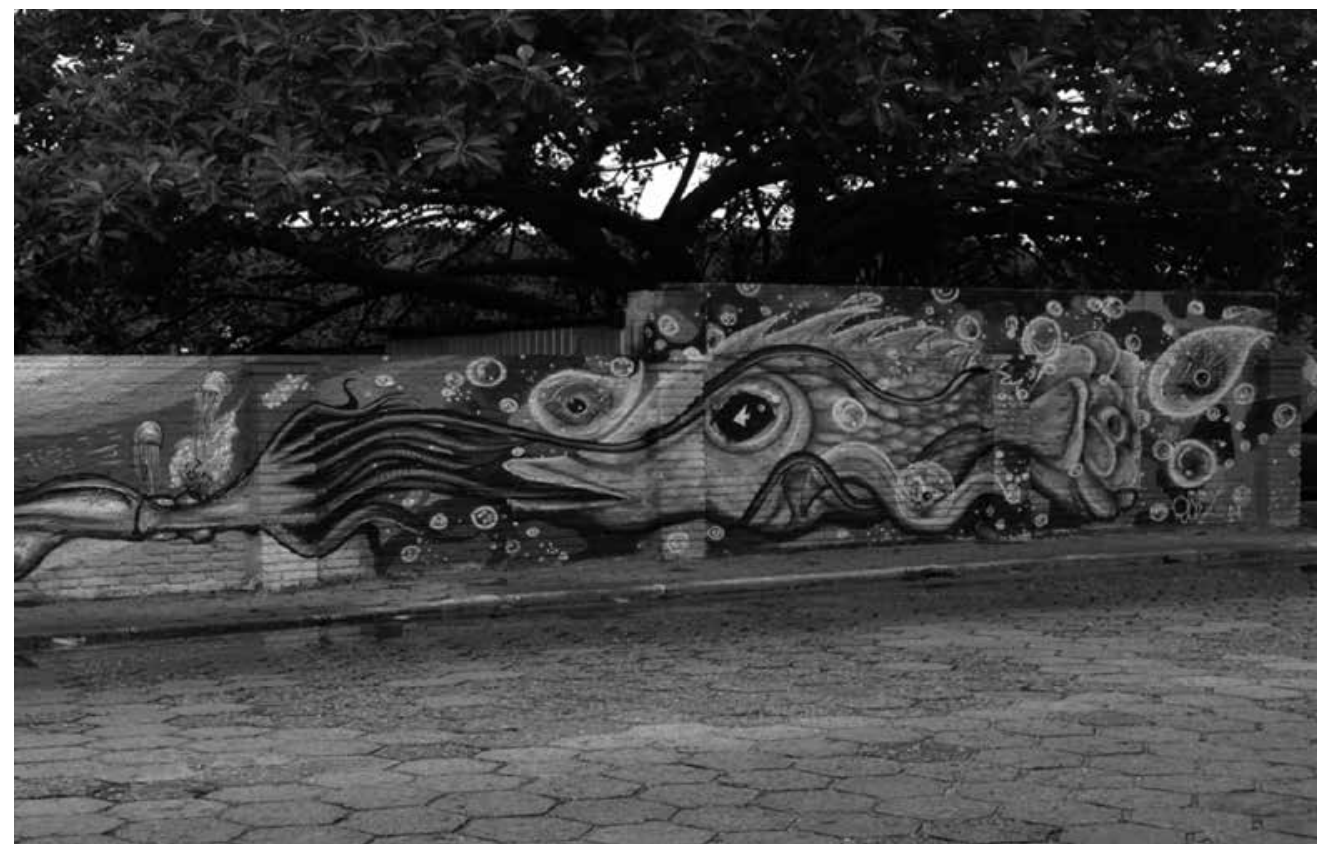

Figura 1 retratam algumas ideias relativas à arte, ao belo e à constituiFonte: Artista Dogz - 2014. Fotografado pela pesquisadora, Avenida Rendeiras- Lagoa da Conceição- Florianópolis, Brasil. ção deste lugar. São descritas as interlocuções frutíferas deste encontro no âmago de uma aldeia em processo de identificação, em constituição enquanto um lugar.

A seguir, evidenciamos algumas imagens dos grafites realizados pelos participantes deste estudo que representam a arte urbana da Lagoa da Conceição, na cidade Florianópolis.

O discurso de Dogz, um dos artistas e responsáveis pela primeira feira anuncia que a arte urbana na Lagoa está relacionada à natureza, como também diz respeito à convivência sociocultural. As questões ressaltadas são relativas à mobilidade urbana, ao saneamento básico, ao tratamento de água tanto para banho, como consumo próprio, o acesso à cultura e ao entretenimento.

A imagem que marca a arte deste grafiteiro é o peixe, que em sua conotação, pode demonstrar a necessidade em visualizar e pensar no mar, na lagoa, na qualidade da água da ilha, de maneira geral, a favor da manutenção desta beleza ambiental natural, e da preservação das espécies, que trazem encanto, alimento, sustento e satisfação. Embora, nesta marca do artista também apareçam sinais do descaso no cuidado da qualidade da água, recentemente imprópria para banho.

O grafite é realizado pelos sujeitos divididos entre e nas cidades, nas quais há uma escrita que colore e grita aos nossos 


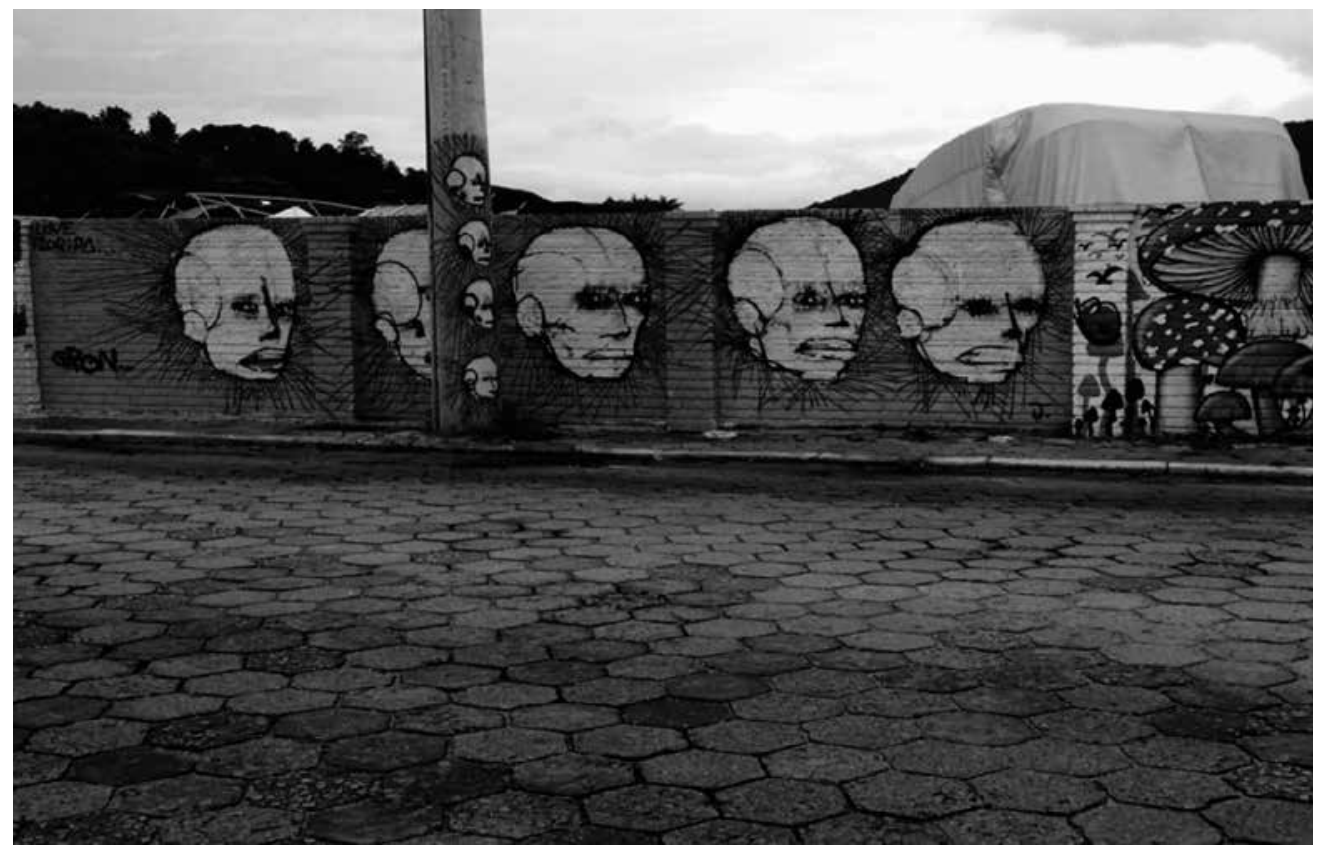

olhos, diz algo, algo sinalizador para uma cidade inteligente, entretanto também não diz. O que é interditado pela cultura permanece sendo escrito e escutar algo deste não dito é o que talvez possa ser articulado com a psicanálise em extensão. $\mathrm{O}$

Figura 2

Fonte: Artista Groon - 2014. Fotografado pela pesquisadora, Avenida Rendeiras- Lagoa da Conceição- Florianópolis, Brasil. grafite marca as cidades. Expõe problemáticas ditas através de imagens, como citado anteriormente, relativas à água e o sustento local, como a pesca.

A pulsão, representante da representação, sustenta um dos pilares da teoria psicanalítica formulada por Freud, é concebida como conceito limítrofe, entre o somático e o psíquico, sempre latente, em busca incessante por satisfação. A pulsão é circular. Escutar algo desta pulsão é vislumbrar como a expressão artística fala da cidade, fala do humano, sujeito ao inconsciente freudiano.

A leitura psicanalítica do conteúdo inconsciente, derivado de conflitos psíquicos reprimidos, desperta as possibilidades de escritas, uma destas a escrita do grafite, enquanto saída para a pulsão, como caminho, ou melhor, dito, como destino sublimação. São letras, desenhos, cores, formas, imagens, simbolicamente pintadas e metaforicamente vistas, artisticamente expostas, imaginariamente compostas, entretanto, contendo censura e certa repressão, pela imposição do não-dito, e ainda interditado pela cultura. 
O grafite da Lagoa pode ser visto, na ótica de um dos grafiteiros, que assina Groon, como arte que expressa sentimentos locais, de diversos universos compartilhados neste contexto. O artista aponta a expressão artística como um cuidado de preservação ambiental, de conscientização quanto ao coletivo, à construção de ciclovias (como ocorre no momento atual na Rua Osni Ortiga), restauração de patrimônios históricos, manutenção da região com pouco crescimento vertical, exemplo de controle social em prol de construção com máximo de quatro andares, bem como os incentivos às feiras, de arte e artesanato, com apresentações culturais, como a do boi de mamão, e a capoeira, dentre outros segmentos que são atrelados à arte de rua deste contexto, a Lagoa da Conceição.

A arte decorativa produzida na Lagoa sinaliza, marca e demarca o desejo de embelezar, colorir, enfeitar a região. É a manifestação do desejo de presentear, de acordo com o olhar e o artefato do grafiteiro. Este questiona: "Qual artista não se sente lisonjeado em grafitar em tamanha beleza?” (Groon). Sigmund Freud (1856-1939), o criador da psicanálise, elucida "o objetivo primário do artista é libertar-se e, através da comunicação de sua obra a outras pessoas que sofram dos mesmos desejos sofreados, oferecer-lhes a mesma libertação" (FREUD, 2006, p.189).

Neste sentido, problematiza-se o público e o privado, sob a luz da psicanálise. O campo artístico põe em questão a própria noção de criação e rompe com a posição central do eu criador. Por meio do que Lacan nos fala, não há o privado, não existe a criação apenas do indivíduo e para o indivíduo, todavia se incita uma articulação entre o público e o privado, entre o fora e o dentro.

Constata-se a função do significante, constatação esta que cria e faz criar, a qual Lacan identificou contendo a primazia do significante, que desliza nesta cadeia, como é análogo e visto na fita de Moebius, figura topológica construída como uma superfície de somente uma face contínua. A operação da cadeia significante é a de criação do próprio significante, seu deslizamento faz emergir, é capaz de gerar, de criar. É o significante que precede ao significado, um axioma lacaniano.

Os processos de criação e produção artísticas podem ser articulados ao processo de sublimação, um dos conceitos psicanalíticos que são entrelaçados à arte. A sublimação "responde à necessidade, para a teoria psicanalítica, de dar conta da origem sexual do impulso criador do homem" (J.D-Nasio, 1997, p.86).

Rivera (2013) retoma a sublimação como operação significante, e salienta que não há como atribuir a criação, enquanto 
processo sublimatório, a um eu. Em referência ao conceito de sublimação, J.-D. Nasio diz "a única noção psicanalítica capaz de explicar que obras criadas pelo homem distantes de qualquer referência à vida sexual, sejam produzidas, ainda assim, graças a uma força sexual nascida de uma fonte sexual" (NASIO, 1997). A origem do processo sublimatório é sexual e o destino é uma realização não sexual. Lacan afirma: "sublime é o ponto mais elevado do que está embaixo".

Os sujeitos são impostos, expostos e sujeitados à linguagem e às marcas que esta última inscreve no corpo. Como tais, são feitos e efeitos do significante (esta marca simbólica), significante ao qual cada sujeito se articula, padecendo seus efeitos. O ser falante é também ser faltante, ser em falta. Na possibilidade da falta é que nascem os desejos, e os destinos dados estão atrelados aos percursos de cada sujeito.

Através da escuta do discurso de outro mensageiro-grafiteiro, existe em Florianópolis, desde 2007, amplo espaço para a arte do grafite, a cidade e em especial a localidade Lagoa da Conceição se agrada com a arte urbana, em relação ao painel, à pintura mural, não à pichação. Há mais de quatro anos o artista pinta e por meio de sua arte, acredita simbolizar a cultura ancestral, as origens, os primórdios. Este sujeito caracteriza sua produção mais próxima da arte expressiva, não da técnica em si, mas priorizando a expressão. Salienta que os murais da Lagoa presenteiam e embelezam o lugar, conseguintemente a cidade. Este artista assina ALMA 73, assinala que sua arte é para todos os lugares, especificamente na Lagoa é mais para a decoração de um lugar privilegiado e belo.
Figura 3

Fonte: Artista Alma 73 - 2014.

Fotografado pela pesquisadora, Avenida Rendeiras- Lagoa da Conceição- Florianópolis, Brasil.

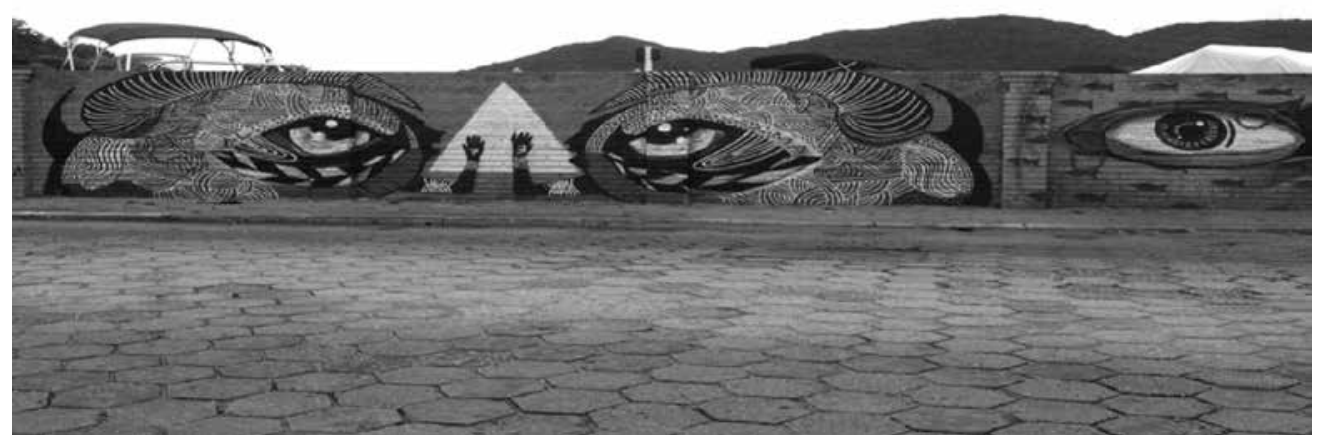


O artista citado associa a arte urbana na Lagoa como uma proposta decorativa, que sugere o belo, ou seja, o efêmero. Com a ideia de resgate dos povos primitivos, das inscrições rupestres, pautadas na cultura ancestral, este artista inscreve sua marca no cenário do grafite da Lagoa. A arte na Lagoa é bem vista, é querida, a receptividade na Lagoa é nítida, embora não exista espaço para a arte rebelde, de protesto e maiores reivindicações políticas. É bem visto e aceito o painel, o muralismo, na apreciação deste artista.

Sabe-se, como afirma Freud, que o belo é o que passa, é o efêmero, que se apresenta, ou melhor, é representado, já anunciando sua perda, sua falta. Embora o autor saliente que as pulsões devam se fazer representar no aparelho psíquico, o psicanalista atenta que o aparelho psíquico é o que produz imagem no sonho, bem como produz piadas, sintomas, lapsos, e ainda marcas, ou seja, o inconsciente profere sinais.

A poética e a magia podem ser articuladas ao Belo, e ao pensamento mágico, que Freud articula como efêmero e transitório. Busca a imortalidade, não a encontra! É Mortal. Nem por isso deixa de ser Belo. Ao perceber a tristeza de um poeta perante a morte da beleza e do belo, Freud elucida, "Não deixei, porém, de discutir o ponto de vista pessimista do poeta de que a transitoriedade do que é belo implica uma perda de seu valor. Pelo contrário, implica um aumento!" E continua: "O valor da transitoriedade é o valor da escassez no tempo. A limitação da possibilidade de uma fruição eleva o valor dessa fruição" (FREUD, 2006, p.317).

O belo é efêmero, é algo de natureza transitória, como a arte de modo geral. Jean Lacoste (2011, p.8) afirma que "a pintura é o símbolo perfeito dessas inclassificáveis artes do belo, que não buscam nem a verdade nem a utilidade, que exprimem, mas em silêncio, que imitam uma realidade imaginária [...]”. Para este autor, ao revisitar conceitos de arte em Platão, "a essência da arte é a mimese, e as obras de arte como imitação, tem o poder da estética, devido à sensibilidade que desperta, provoca e se dirige, em última análise, ao corpo do homem" (LACOSTE, 2011, p.17).

Para este grafiteiro, Alma 73, o interessante é a expressão crua, como se o pensamento também fosse primitivo. Como se o homem pudesse, pelo menos por algum momento, deslocar-se do pensamento civilizado, moderno, pós-moderno, e se fundamentasse na sensação. Os primeiros impactos, a impressão primitiva, como exemplo, cita os desenhos que homens deixaram nas cavernas, ou os índios em suas tribos, resgatando as primeiras informações, sem o filtro capitalista, 
sem tanto consumo.

Articula-se aqui um volume freudiano "O mal estar na cultura”, ou dependendo da tradução, "o mal estar na civilização". No qual, o autor denota que o ser humano é privado de conhecer a respeito de alguns conteúdos, estes últimos reprimidos, filtrados culturalmente. Desta forma, o mal estar é provocado, pois, o homem civilizado não pode alcançar a completude idealizada, não pode fazer tudo e apenas obter prazer, satisfação. Há sofrimentos vividos.

Sofremos, esclarece Freud, por motivos envoltos em três diferentes esferas, as quais são primeiramente os fatores relativos ao mundo externo e suas adversidades, como terremotos, furacões e tantas outras tragédias climáticas e escassez. Na segunda esfera são as relações entre os humanos, os relacionamentos, os quais são os principais motivos que nos fazem sofrer, no ponto de vista do autor. E na terceira esfera estão os percalços da vida de cada sujeito, as doenças, velhice e morte.

A arte, e neste artigo a arte de rua grafite, é manifestação de marcas inconscientes, repletas de significantes latentes. Por meio do discurso dos sujeitos grafiteiros é que se pode escutar algo das singularidades imageticamente expostas nos muros, divididas entre o dentro e o fora, entre estar só e estar em civilização, entre culturas distintas e conviventes nas cidades inteligentes.

\section{Considerações finais}

Lacan adverte, "o inconsciente é estruturado como uma linguagem - o que se relaciona com um campo que hoje nos é muito mais acessível do que no tempo de Freud" (LACAN, 20o8, p. 27). E continua, “[...] antes mesmo que se inscrevam as experiências coletivas que só são relacionáveis com as necessidades sociais, algo organiza esse campo, nele inscrevendo as linhas de força iniciais" (LACAN, 2008, p. 28). Mais, ainda, o autor esclarece, "É a função que Claude Lévi-Strauss nos mostra ser a verdade totêmica, e que reduz sua aparência - a função classificatória primária” (LACAN, 2008, p. 28).

Uma escrita é marcada pelo grafite nos lugares,"que, conforme o totem, o tipo, o interesse, a fama (vale dizer, a presença em todo canto da cidade) são reproduzidas por novos grafiteiros - transformam tudo em monumento da língua” (COSTA-MOURA; LO BIANCO, 2009).

A maneira crua como é colocada a arte expressiva nos muros e paredes da Lagoa, é de fácil absorção, pelas pessoas que passam e olham a mensagem rápida, cada um faz seu julgamento, 
mas a mensagem é dada, a expressão está ali. Este resgate, do elemento expressivo, neste caso, não significa voltar às origens da linguagem, mas antes, que a linguagem é própria origem (COSTA-MOURA; LO BIANCO, 2009). Somos todos atravessados pela linguagem, enquanto seres dotados de desejos, não de vontades, mas sim de desejos. A fome, a sede e a linguagem, por exemplo, são provas de que o homem antes de tudo é movido pelos seus desejos.

Falar em desejo é falar em falta, para a teoria psicanalítica. Freud articulou o desejo à falta de completude, ou seja, precocemente os seres humanos se deparam com a insatisfação, melhor dito, com a ausência de satisfação. E aí está a marca da falta, onde é preciso se ver em falta para se lançar ao desejo, isso de modo inconsciente. Lacan reflete a teoria freudiana e nos diz: "[...] ensina o discurso analítico sobre a velha ligação com a nutriz, mãe ainda por cima, como se, por acaso, tendo, por trás, a história infernal de seu desejo e tudo aquilo que vem em seguida" (Lacan, 2008, p. 21).

O grafite é marca dos sujeitos. Sujeitos ao inconsciente, "o grafite aponta, no sentido de impulso desencadeante contra todo poder central: o poder político, o econômico, o lingüístico. Vai contra o império - o significante "AMO", conforme Lacan - em todo seu sentido e significação" (SILVA, 2014, p.83).

Sempre há no grafite uma forma de expressão que levante uma problemática. Um desenho mural, escrito, manifestação que surge "num hibridismo, entre os impulsos primários de satisfação de desejos inconscientes e a secundária manifestação social de revolta contra o estabelecido e o institucional" (SILVA, 2014, p.82).

Neste sentido, a arte urbana pode não dizer algo no momento em que foi produzida, entretanto posteriormente vai dizer algo, porque a arte tem esse poder, como a vida, é transitória e pode mudar, simbolicamente. A arte tem essa função, além do belo, transpor a informação, ela comunica diversas coisas com o passar do tempo. A arte urbana expressa amiúde problemáticas relativas às diversas marcas de condições humanas. Todas têm sua origem em alguma questão, é a busca de alguma resposta.

Lacan nos diz "o homem encontra sua casa num ponto situado no Outro para além da imagem de que somos feitos". Ou seja, ele institui "uma caracterização lapidar do lugar do sujeito" (RIVERA, 2013). Melhor dito, de sua falta de lugar. Lacan afirma que como disse Freud, o sonho é um rébus, portanto, é uma escrita.

"Nas cidades de hoje, algumas centenas de jovens empunhando seus sprays, remontam às origens da escrita, escrevendo nas 
coisas" (COSTA-MOURA; LO BIANCO, 2009). O grafite pode ser interpretado a partir de uma escrita, repleta de conteúdos manifestos e também latentes, individuais e coletivos. Isto denota que há transeuntes que se identificam com as obras na cidade.

Diante do exposto é dito, as metáforas, ou as representações escritas nas paredes, nos muros, em postes e caixas de eletricidade, ou em quaisquer outros lugares, são simbolizadas pelas ideias e os afetos, ou seja, os representantes da pulsão. Esta última, contínua, incessante, limítrofe entre o psíquico e o somático. Metaforicamente a sede, o lugar, das paixões.

\section{NOTAS}

1. Formações de compromisso: são as formações do inconsciente, propostas por Freud, os sonhos, os atos falhos, os chistes e os sintomas.

\section{Referências}

AMARAL, Aracy A. Arte para quê? São Paulo: Nobel, 1984. BARDIN, Laurence. Análise de conteúdo. Lisboa: 70, 1977. COSTA-MOURA, Fernanda; LO BIANCO, Anna, C. Escrever nas coisas: a utopia contemporânea na linguagem dos adolescentes. Dossiê A Adolescência entre a psicanálise e a educação. Estilos da clínica. v. 14 n. 27 São Paulo, 2009.

FREUD, Sigmund. Psicologia de grupo e a análise do ego (1921). In: . Além do princípio de prazer, psicologia de grupo e outros trabalhos. Rio de Janeiro: Imago, 2006.

FREUD, Sigmund. O Ego e o Id (1923). In: O Ego e o Id e outros trabalhos. Rio de Janeiro: Imago, 2006. . O interesse científico da psicanálise (1913). In:

Totem e tabu e outros trabalhos. Rio de Janeiro: Imago, 2006.

. O inconsciente (1915). In: . A história do movimento psicanalítico, artigos sobre a metapsicologia e outros trabalhos. Rio de Janeiro: Imago, 2006.

. O interesse da psicanálise do ponto de vista da ciência da estética (1913). In: Totem e tabu e outros trabalhos. Rio de Janeiro: Imago, 2006.

. Esquecimentos, lapsos da fala, equívocos na ação, superstições e erros (1901). In: Sobre a psicopatologia da vida cotidiana. Rio de Janeiro: Imago, 2006.

Sobre a transitoriedade (1915). In: A história do movimento psicanalítico, artigos sobre a metapsicologia e outros trabalhos. Rio de Janeiro: Imago, 2006. 
GIL, Antonio Carlos. Amostragem na pesquisa social. In: Métodos e técnicas de pesquisa social. 5. ed. São Paulo: Atlas, 1999. Cap. 9, 98-106 p.

GITAHY, Celso. O que é graffiti? São Paulo: Brasiliense, 2012.

LACAN, Jacques (1986) Le Séminaire, Livre VII: L’Éthique de la Psychanalyse. Paris: Seuil. (2001) La Méprise du Sujet Supposé Savoir (Conferência proferida no Institut Français de Naples em 1967). In: Autres Écrits. Paris: Seuil, p. 329-339.

LACAN, Jacques. O Seminário de Jacques Lacan. Livro 11: Os quatro conceitos da psicanálise (1964). Texto estabelecido por Jacques-Alain Milher. Rio de Janeiro: Jorge Zahar Editor, 1988. Tradução Le Séminaire de Jacques Lacan. Livre XI: Les quatre concepts fondamentaux de la psychanalyse (1964).

LACAN, Jacques. O seminário de Jacques Lacan. Livro 20: Mais, ainda. Texto estabelecido por Jacques-Alain Milher. Rio de Janeiro: Jorge Zahar Editor, 2008.

LACOSTE, Jean. A filosofia da arte. Tradução de Álvaro Cabral. 2. ed. Rio de Janeiro: Zahar, 2011.

LIMA, T. A. A.; SCHMIEGELOW, S. S.; PERASSI, R. L.S. A comunicação da marca Dove e o feminino na Psicanálise. Razón y Palabra. v. 20, n. 93, 2016a.

LIMA, T. A. A.; SCHMIEGELOW, S. S.; PERASSI, R. L.S.; SOUSA, J.G.N. Grafite: Mídia e Conhecimento em Interlocução Psicanalítica. Razón y Palabra. v. 20 n. 93, 2016 b.

MARCONI, Marina de Andrade; LAKATOS, Eva Maria. Técnicas de pesquisa. In: . Fundamentos de Metodologia Científica. 5. ed. São Paulo: Atlas, 2003. cap. 9, p.174-214.

NASIO, J. - D. Lições sobre os sete conceitos cruciais da Psicanálise. Tradução Vera Ribeiro. Rio de Janeiro: Zahar, 1997.

ORLANDI, Eni. Cidade dos sentidos. Campinas: Pontes, 2004. PERASSI, Richard. Roteiro da Arte na produção do conhecimento. Campo Grande, MS: EDUFMS, 2005.

RIVERA, Tania. $O$ avesso do imaginário: arte contemporânea e psicanálise. São Paulo: Cosac Naify, 2013.

ROCHA, Décio; DEUSDARÁ, Bruno. Análise de conteúdo e análise do discurso. Disponível em: <http://www.scielo.br/ pdf/alea/v7n2/a1ov7n2.pdf>. Acesso em: ago.2014.

SILVA, Armando. Atmosferas urbanas: grafite, arte pública, nichos estéticos. São Paulo: Editores Sesc, 2014.

Recebido em: 05/04/15

Aceito em: 04/01/16 
RICHARD PERASSI LUIZ DE SOUSA

perassi@cce.ufsc.br

Possui Doutorado em Comunicação e Semiótica pela Pontifícia Universidade Católica de São Paulo (PUC/SP), 20o1. É Professor na Universidade Federal de Santa Catarina (UFSC).

\section{TAÍS AZAMBUJA ALVES DE LIMA}

tais.azambuja84@gmail.com

Psicanalista, psicóloga, mediadora de conflitos e mestranda no Programa de Pós-Graduação em Engenharia e Gestão do Conhecimento pela Universidade Federal de Santa Catarina (EGC - UFSC). 